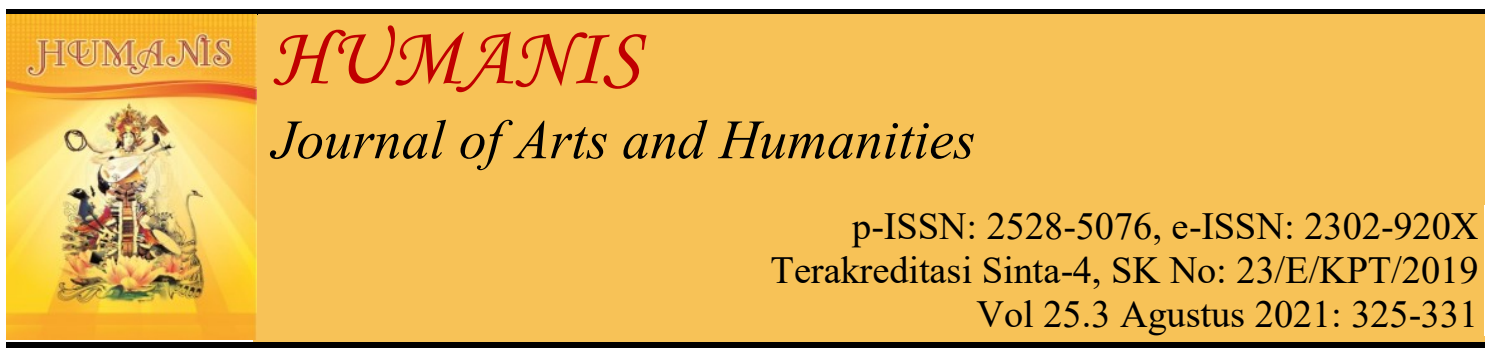

\title{
Ekranisasi Novel Asih Karya Risa Saraswati
}

\author{
Ni Komang Maldawati \\ Universitas Udayana, Denpasar, Bali, Indonesia \\ Email Koresponding: Maldawaty92@gmail.com
}

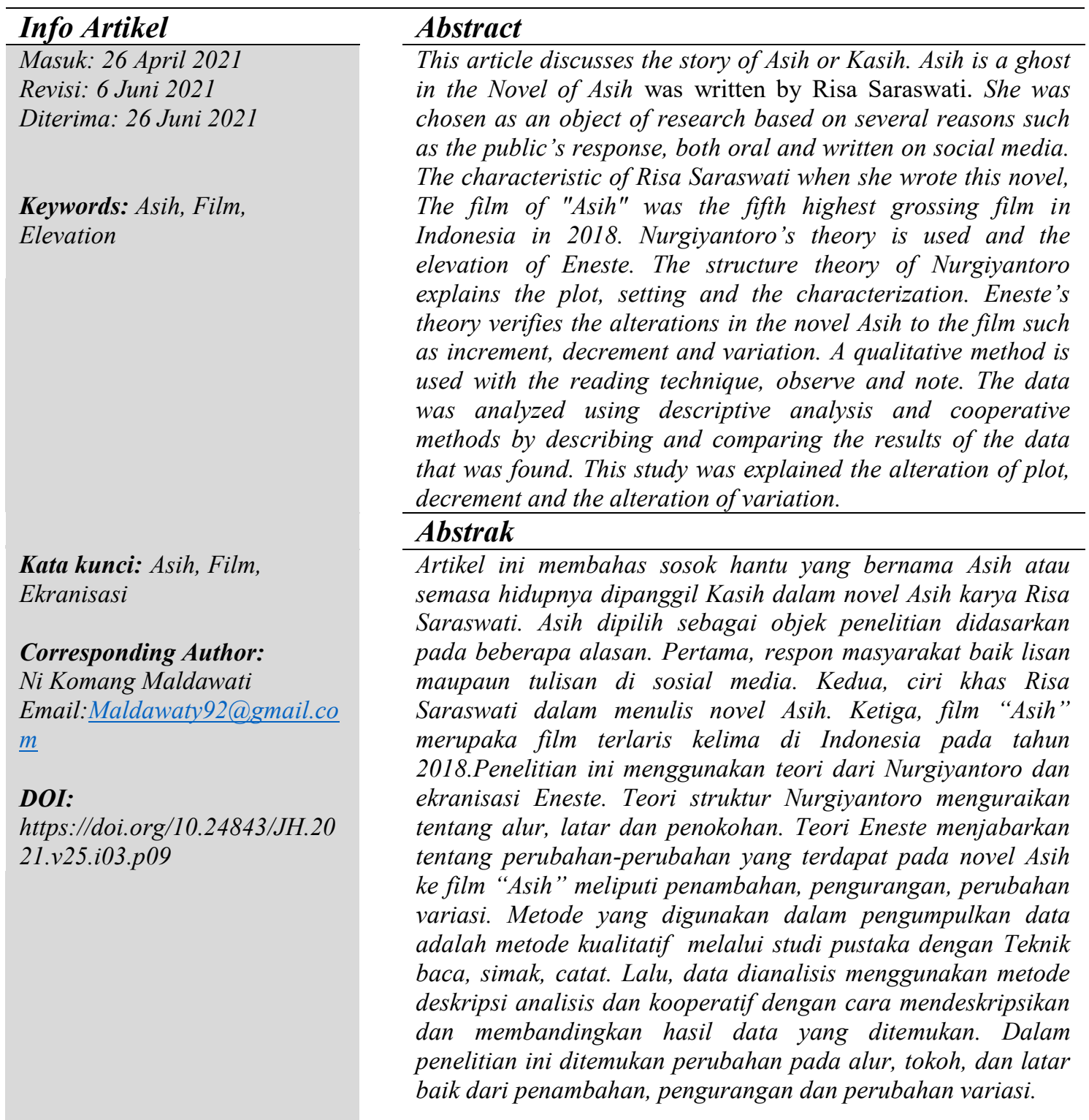




\section{PENDAHULUAN}

Karya sastra memberikan dampak positif terhadap perkembangan dunia perfilman Indonesia (Prima, dkk, 2018:45). Perfilman Indonesia semakin maju. Tidak jarang banyak film yang diproduksi di Indonesia diadaptasi dari sebuah karya sastra (Sri, 2018:1). Novel merupakan karya sastra yang diminati dijadikan film. Novel merupakan sebuah karya sastra yang berbentuk fiksi (Siti,dkk, 2018:220). Ekranisasi adalah perubahan audio visual dari bentuk novel ke berbentuk film (Muhammad Ali , 2017:154).

Banyak peubahan yang dilakukan saat ekranisasi dibuat salah satunya dari durasi yang bertujuan untuk memilih peristiwa yang penting saja hanya ditampilkan di film(selly, dkk, 2018:382). Selain itu, membaca membutuhkan waktu yang lumayan lama sedangakan meninton film hanyan membutuhkan waktu yang sebentar (eko dan sri, 2018:3). Menurut Eneste (1991:61-66) perubahan dari novel ke film membutuhkan beberapa perubahan seperti penambahan, pengurangan, dan perubahan bervariasi yang menyebabkan bebetapa hal akan berubah disaat difilmkan. Hingga, film tersebut tak sepenuhnya terlihat asli seperti dinovel (Shifa, dkk, 2020:140). Tetapi pengarang tidak akan mengabaikan/menghilangkan unsur cerita dalam ceritanya, karena mereka tau bahwa kesuksesan sebuah novel berada di sudut pandang pembaca yang sudah dibayangkan oleh para pembaca (Meizy, dkk, 2020:174). Larisnya sebuah novel menjadi dayabtarik dari produsen dan sutradara untuk memfilmkan novel tersebut (Musyafir, dkk, 2017:76).

Novel merupakan karya sastra yang menceritakan kehidupan dengan berbagai hal yang mengisahkan kehidupan di dunia nyata (Prastika, dkk 2013:47). Fenomena ini nendapatkan ketertarikan para pembaca, hal ini membuat ekranisasi semakin meningkatkan ketertarikan di kalangan masyarakat (Sanin, dkk, 2017:409). Ini membuktikan bahwa karya sastra sangat layak untuk dijadikan sebuah film yang bisa memikat para masyarakat (isna, 2019:83). Salah satu novel yang diadaptasikan menjadi film adalah Asih karya Risa Saraswati. Novel Asih merupakan novel keenam yang ditulis oleh Risa Saraswati. Sebelumnya Risa Saraswati sudah meliris lima novel yang berjudul Danur, Gerbang Dialog Danur, Maddah, Sunyaruri, Rasuk Novel Asih menceritakan seorang perempuan bernama Kasih yang menjadi seorang pembantu rumah tangga sekaligus pengasuh di Bandung. Namun, ternyata selama bekerja di Bandung. Kasih melakukan perbuatan yang tercela sehingga membuatnya berbadan dua dan pris itu tak mau bertanggungjawab. Karena itu, ia mengalami frustrasi dan memilih bunuh diri dengan cara gantung diri.

Novel Asih menjadi salah satu novel dari novelis Risa Saraswati yang diberikan judul yang sama dengan novelnya yang disutradarai Awi Suryadi. Film "Asih" diliris pada 11 Oktober 2018 dibuat oleh MD Pictures dan Pichouse film. Menurut Wikipedia film ini meraih 1.714 .798 penonton dan mendapatkan peringkat kelima dalam top ten film di Indonesia pada tahun 2018.

Pemilihan novel Asih sebagai objek kajian ini berdasarkan pada beberapa alasan, yaitu tanggapan dari masyarakat terhadap novel yang ditulis oleh Risa Sarawati, banyaknya review yang membahas novel Asih dari blog dan situs resmi seperti mymulia.wordpress.com,Wikipedia, Gramedia, Kompas, baik sebelum difilmkan maupun sesudah difilmkan. Ciri khas Risa Saraswati dalam menceritakan sosok Kasih dengan 
memberikan kesan yang di luar logika manusia, membuat banyak pembaca merasa penasaran untuk membaca novel Asih. Kekuatan novel Asih terletak pada pengemasan alur cerita yang membuat pembaca ikut terbawa suasana saat membacanya. Tidak hanya itu, tokoh dan latar yang ada di dalam novel Asih semakin menguatkan cerita tentang sosok Kasih. Pengadaptasian novel Asih ke film Asih mengalami perubahan yang membuatnya menarik untuk diteliti. Penelitian ini difokuskan untuk meneliti struktur novel Asih, terutama komponen alur, latar, dan penokohan yang diekranisasi ke filmnya.

\section{METODE DAN TEORI}

Dalam penelitian ekranisasi ini menggunakan metode kualitatif dengan menafsirkan temuan yang ada kemudian disusul dalam bentuk deskripsi.

Teknik yang digunakan adalah teknik membaca Novel Asih, menyimak film Asih dan mencatat perbedaan yang ada lalu menganalisis data tersebut dengan metode perbandingan dan deskripsi analisis. Hasl analisis disajikan dalam bentuk skripsi.

\section{Teori Struktural}

Teori struktural adalah teori tahap permulaan untuk mengerti sebuah karya sastra dari unsur intrisik maupun ekstrisik (gadis, 2019:7). Penelitian ini mengkaji menggunakan teori struktur dari Nurgiyantoro yang memfokuskan menggunakan unsur pembangun, yaitu latar, alur, dan penokohan. Menurut Teeuw (1985:154), analisis struktural merupakan langkah awal agar memudahkan seseorang untuk memahami makna yang ada.

Teori Ekranisasi

Ekranisasi adalah pengangkatan sebuah karya sastra ke dalam film. Eneste (1991:61-66) memberitahukan bahwa dalam pelayarputihkan seuatu novel akan ada perubahan-perubahan yaitu.

a) Penambahan

Penambahan bertujuan untuk mendapatkan hal baru yang tanpa mengurangi tujuan yang ada di dalam novel tersebut. Penambahan biasanya dilakukan untuk mendapat hal yang berbeda dengan di novel (Devi, 2016:19)

b) Pengurangan

Pengurangan biasanya dilakukan karena ada beberapa faktor mendukung seperti durasi pada film, tokoh atau latar yang tidak perlu ditampilkan di dalam film karena tidak terlalu penting.

c) Perubahan Variasi

Pelayarputih juga mungkin akan terjadi variasi tertentu dalam proses ekranisasi (Eneste 1991:65). Perubahan perubahan bervariasi ini agar penonton dapat menikmati alur film kendati tak di gambarkan secara detail ketika cerita tersebut termuat dalam novel ( Hasina, 2016:75)

\section{HASIL DAN PEMBAHASAN}

\section{Analisis Struktur}

\section{Alur}

Alur menjadikan segala sesuatu yang dikisahkan berimajiantif (Silvia, dkk 2018:122). Tahap ini digunakan untuk meneliti alur novel Asih, Tahap awal merupakan pengenalan tokoh kasih. Saat ini banyak yang mengenal sosok Kasih dengan panggilan Asih. Kasih dilahirkan tepat pada bulan Ramadhan setelah ibunya shalat tarawih di masjid. Pada tahap tengah, konflik muncul ketika Kasih menyukai anak majikannya yang bernama Angga. Ternyata Angga sudah memiliki kekasih dan membuat Kasih sedih. Hal ini terdapat pada kutipan berikut. Tahap akhir, setelah Kasih bunuh 
diri, dia menjadi sosok hantu yang selalu menganggu penghuni rumah tempat dia mengakhiri hidupnya. Hingga akhirnya majikan maupun para pekerja tidak sanggup lagi untuk tinggal di rumah tersebut

\section{Tokoh}

Tokoh yang terdapat pada novel Asih adalah Risa tokoh utama di dalam novel yang sekaligus penulis novel Asih, Kasih tokoh utama lainnya yang diceritakan dalam novel, Karman adalah seorang yang senang merayu dan membuat Kasih hamil lalu mengakhiri hidupnya, Si Mbok adalah tokoh dimana Kasih bekerja di majikan barunya dan dianggap ibu sendiri oleh asih dan beberapa tokoh lainnya yang tidak dijelaskan secara detail.

\section{Latar}

a. Latar tempat pada novel Asih yaitu kota Bandung, komplek rumah nenek Risa, Desa Sukaraja, dan masjid

b. Pada novel Asih, banyak beberapa latar waktu yang digambarnya secara jelas oleh penulis seperti waktu bulan Ramadhan. Pergantian waktu seperti pagi, siang, malam pun dijelaskan baik langsung maupun tidak langsung. Azan Isya yang menunjukan secara tidak langsung menunjukan waktu malam hari, pukul setengah tiga subuh menunjukan waktu pagi hari, dan pukul satu dini hari menunjukan waktu tengah malam. Novel asih lebih dominan dengan latar pada malam hari dikarenakan hantu Kasih hanya bisa datang untuk bercerita pada waktu malam hari.

c. Latar sosial yang tergambar dalam novel Asih adalah kehidupan disaat Kasih masih hiduppada saat jaman setelah penjajahan Belanda. Terbukti dari beberapa bangunan yang masih khas dengan ornamen-ornamen Belanda.

\section{Ekranisasi Novel $\boldsymbol{A}$ sih}

1. Ekranisasi alur dalam novel Asih

Ekranisasi alur ini dibagi menjadi tiga bagian yaitu penciutan, penambahan, perubahan bervariasi. Aspek penciutan merupakan penciutan yan terdapat pada novel Asih dalam filmnya. Artinya, beberapa bagian yang ada di dalam novel tidak ditampilkan pada filmnya. Aspek penciutan ditemukan 10 deskripsi bagian antara lain: B1 (3), B2 $(1,2)$, B5 $(1,2)$, $\mathrm{B} 6(1), \mathrm{B} 10(1,2,3), \mathrm{B} 11(1), \mathrm{B} 12(1,2,3)$, B13(1,2), B14 (1,2,3), B20(1). Salah satu penciutannya yaitu pada data B1(3) ketika Risa menceritakan saat Kasih dilahirkan pada saat bulan Ramadhan di desa Sukaraja. B2(1) ketika Kasih pulang dari masjid dan bertemu seorang pemuda tambun. Ia dilamar oleh pemuda tersebut tetapi kasih menolak pemuda tersebut. Kategori aspek penambahan ditemukan 12 bagian adegan penambahan. Contoh aspek penambahan berapada pada data S33 yaitu ketika Ita menutup pintu kamar. Andi menghampiri Ita dan meminta ijin untuk menaruh boneka yang diberikan bidan Sekar untuk di simpan di dalam lemari. Mereka pun mengobrol tentang kekhawtiran Ita tentang penyakit ibu yang semakin lama semakin parah pikunnya. Setelah mereka selesai mengobrol, Ita ingin mencoba untuk tidur namun tiba-tiba terdengar suara ketukan tiang listrik. Ita mencoba menghitung sambil melihat jam di dinding yang menunjukan pukul 10 malam. Namun, saat dihitung ketukan tersebut ternyata berjumlah 11 ketukan yaitu lebih dari angka waktu malam itu. Bagian perubahan bervariasi di dalam alur cerita terdapat beberapa bagian yaitu $\mathrm{B} 8(3)$, B15(1), B16(2), B17(2), B18(2), B18(3), B19(1) mengalami perubahan ketika dijadikan kesebuah film ditemuka di 7 scene yaitu S4, S13, S21, S45, S50, S57, S58. Salah satu bagian pada novel bayi itu menghilang saat ditaruh di boksnya, 
hal ini terdapat pada B8(1) mengalami perubahan variasi. Pada film S45, Ita memandikan Amelia di belakang rumahnya. Tiba-tiba pintu di bekalang rumahnya menutup pelan-pelan membuat Ita terus menoleh kebelakang sampai akhirnya pintu itu tertutup dengan keras membuat Ita kaget dan menoleh pintu itu. Ketika ia kembali melanjutkan memandikan Amelia. Amelia hilang. Ita terus mencari Amelia di tempat ia memandikan Amelia. Bukan Amelia yang ditemukan malah kepala dari sosok perempuan itu muncul dari tempat mandi Amelia. Ita pun berteriak.

\section{Ekranisasi tokoh dalam novel Asih}

Ditemukan 5 data penciutan tokoh dalam novel ke film Asih yaitu: Peter Cs, Angga, si Mbok, Oma Fat, Kasman. peneliti menemukan 5 tokoh penambahan dalam film yaitu bidan Sekar, ibu Andi, Abah, Hansip dan Penjual Nasi Goreng. , terdapat satu tokoh yang mendapatkan perubahan bervariasi dalam novel ke film. Tokoh tersebut adalah Kasih atau sering disebut Asih. Diceritakan Kasih adalah seorang gadis yang feminim, taat beribadah dan suka membantu orang tuanya.

\section{Ekranisasi Latar pada Novel Asih}

kategori aspek penciutan latar terdapat 4 latar. Bagian-bagian tersebut, yaitu Desa Sukaraja B1(3), rumah majikan asih B10(3), toko kelontong B7(1), dan yang terakhir adalah kamar Risa B3(1). aspek penambahan latar dari nove ke film berjumlah 4 yaitu rumah kosong S3, pohon S4, Rumah bidan Sekar S47, dan Rumah abah S48. kategori perubahan variasi latar berjumal 2 latar. Perubahan variasi terjadi pada B16(3) kamar tidur ke S4 pohon. B8(3) boks bayi ke S45 halaman belakang rumah

\section{SIMPULAN}

Disimpulkan bahwa dari aspek alur terdapat penciutan alur seperti data B1 (3) ketika risa menceritakan saat kasih dilahirkan pada saat bulan Ramadhan di desa sukaraja. Aspek penambahan alur contohnya pada data S33 yaitu ketika ita menutup pintu kamar. Aspek perubahan variasi alur contohnya pada data B8(1) bayi itu menghilang saat ditaruh diboksnya pada film S45, ita memandikan amelia dibelakang rumahnya dan amelia menghilang.

Aspek menciutan pada tokoh terjadi juga pada novel asih ke film asih salah satunya tokoh peter Cs, angga, si Mbok, oma Fat Kasman serta ada pula penambahan tokoh yaitu bidan Sekar ibu Andi, abah. Aspek perubahan variasi dalam novel ke film dilihat dari adanya perubahan penggambaran tokoh yaitu tokoh kasih atau sering disebut asih.

Aspek penciutan terdapat 4 latar yaitu desa sukaraja rumah majikan asih toko kelontong dan kamarisa. Tidak hanya itu aspek penambahan latar terdapat 4 data yaitu rumah kosong,pohon, rumah bidan Sekar, dan rumah Abah. Kategori aspek perubahan variasi terjadi pada kamar tidur ke pohon dan boks bayi ke halaman belakang rumah Peneliti berharap agar penelitian tentang ekranisasi lebih diperdalam tidak hanya dari segi struktural tetapi bisa dari segi lainnya seperti sosial, adat dan sebagainya.

\section{DAFTAR PUSTAKA}

Aderia, P., WS, H. W. H., \& Zulfadhli, Z. (2013). Ekranisasi Novel ke Film Surat Kecil untuk Tuhan. Jurnal Bahasa dan Sastra, 1(2), 46-59.

Adha, Isna Dia'ul. (2019). Ekranisasi Film "Pesantren Impian" Karya Asma Nadia. Jurnal Kata, 3(1) 
Ardianti, Eka Retno, Sri Wwidayati (2018). Ekranisasi Cerpen Filosofi Kopi Karya Dewi Lestari (Dee) Ke Dalam Film Filosofi Kopi Sutradara Angga Dwimas Sasongko Sebagai Aternatif Bahan Ajar Di Sekolah Menengah Atas. Jurnal Elsa, (16) 2.

Alfathoni, Muhammad Ali Mursid. (2017).Ekranisasi unsur naratif dalam film cahaya cinta pesantren sutradara Raymond Handaya. Jurnal Proporsi, (2)2.

Amalia, Septiana Gadis, I.G.A.A. Mas Triadnyani.2019. Dilan(Dia Adalah Dilanku 1990) Karya Pidi Baiq: Perspektif Ekranisasi. Denpasar. Universitas Udayana.

Aniskurli, Syifa, Sri Mulyati, Syamsul Anwar. (2020). Ekranisasi Novel Dua Garis Biru Karya Lucia Priandarini Ke Bentuk Film Dua Garis Biru Karya Gina S.Noer dan Implikasinya Terhadap Pembelajaran Sastra Di SMA. Jurnal Wahana Pendidikan, (7)2.

Carmila Selly Dwi, Mursalim, Alfian Rokhmansyah. (2018). Transformasi Novel Sabtu Bersama Bapak Karya Ditya Mulya Menjadi Sabtu Bersama Bapak Kayra Monty Tiwa: Kajian Ekranisasi: Jurnal Ilmu Budaya, (2)4

Damayanti, S., Wedayanti, N. P. L., \& Sari, I. A. L. (2018). Alih Wahana Cerita Rakyat Terjadinya Pulau Bali dari Buku Cerita Bergambar Menjadi Anime. Pustaka: Jurnal Ilmu-Ilmu Budaya, 18(2), 118-125.

Eneste, Pamusuk. 1991. Novel dan Film. Flores: Nusa Indah.
Fadila,Siti, Sulaiman Juned, Nursyirwan. (2018). Ekranisasi Novel Ke Film Surga Yang Tak Dirindukan 2 Dengan Kajian Interteks. Widya Parwa, (46)2

Keniloreah Meizy, Abdul Malik, Legi Elfitra. (2020). Ekranisas Novel Rasuk Karya Risa Saraswati Ke Dalam Film Rasuk Karya Ubayfox Dan Pemanfaatannya Sebagai Alternative Bahan Ajar Pada Mata Kuliah Prosa Fiksi Dan Drama Di Pendidikan Bahasa Dan Sastra Indonesa Umrah. Student Online Journal, (1)1.

Musyafir, Gazali Lembah, Nurhaya Kangiden. (2017). Ekranisasi Novel Tenggelamnya Kapal Van Der Wijck Ke Dalam Film(Pendekatan Struktural). Bahasantodea, (5)2.

Nurgiyantoro, B. 1995. Teori pengkajian fiksi. UGM press.

R. Hasina Fajrin. (2016). Ekranisasi novel ke film surge yang tak dirindukan. Sawerigading, (22)1.

Sanin, Mohamad; Matildis Banda, Maria; Mas Triadnyani, I G.A.A. (2017). Cinta Suci Zahrana Karya Habiburrahman El Shirazy: Alih Wahana dari Novel ke Film. Jurnal Humanis Fakultas Ilmu Budaya Unud, (19)1.

Teeuw, A. 1985. Sastra dan Ilmu Sastra: Pengantar Teori Sastra. Jakarta: Dunia Pustaka Jaya.

Yanti, Prima Gusti, Syarif Hidayatullah, Richa Khairani. (2018). Representasi Ekranisasi Novel 
Dear Nathan Karya Erisca Febriani. Jurnal IMAJERI, (1)1.

Yanti, D. S. A. (2016). Ekranisasi Novel Ke Bentuk Film 99 Cahaya Di Langit Eropa Karya Hanum Salsabiela Rais dan Rangga Almahendra. Bahasa Dan Sastra Indonesia-S1, 5(1).

Wahyuni, S. (2018). Ekranisasi Novel Danur Karya Risa Saraswati ke dalam Film Danur Karya Sutradara Awi Suryadi. Bapala, 5(1). 